\title{
Social Supports for Community Corrections Clients: Risk Factors or Protective Factors?
}

\author{
Lacey Schaefer ${ }^{a}$, Gemma C. Williams ${ }^{a}$, and Tenille Ford ${ }^{a}$

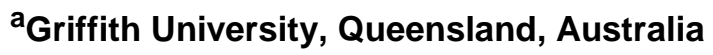

\begin{abstract}
The significance of social supports throughout an individual's life-course has been widely documented. However, there is ambiguity about whether social supports are likely to encourage or discourage reoffending. The current study qualitatively examines the kinds of support offered to a sample of probationers and parolees by their social support networks through a thematic analysis of transcripts gained from semi-structured interviews with 15 clients and 16 of their "PoPPs" (parents/partners/peers of probationers and parolees). Results indicate that there are several forms of support provided by correctional clients' loved ones. These forms of support were well-received by the clients who considered them beneficial, although the findings demonstrate that social supports are not universally prosocial, and that some forms of support may be criminogenic rather than protective factors.
\end{abstract}

JQCJC "Qualitative Criminology," (2022)

Vol. 11, Iss. 1, 115-141

ARTICLE HISTORY

Received 5/5/2021

Accepted 6/21/2021

\section{KEYWORDS}

Risk factors, protective factors, parole, social support, emotional support

Social supports are often identified as an important tool for managing correctional clients, with scholars acknowledging that these individuals may be a key element to reducing criminal behaviour (Executive Session on Community Corrections, 2017; Schaefer, Cullen, \& Eck, 2016; Solomon et al., 2008). However, there are differing views as to whether the influence of an probationer or parolee's social support network contributes to desistance or may inadvertently encourage reoffending (Macklin, 2013; Schaefer, Moir, \& Williams, 2019; Schaefer, Townsley, \& Hutchins, in press). Moreover, while there is a substantial body of research that examines how these relationships operate during the onset of criminal behaviour (Cullen, 1994; Sullivan, Childs, \& Gann, 2019), their correlation with recidivism (Andrews \& Bonta, 2010; Wooditch, Tang, \& Taxman, 2014), or how they operate when an individual is in custody (Duwe, 2018; Jiang, FisherGiorlando, \& Mo, 2005; Jiang \& Winfree, 2006), there has been little research exploring the influence of these relationships when the person is subject to community supervision.

DOI: https://doi.org/10.21428/88de04a1.69f6e14b 
Understanding what kinds of support are provided by the social supports of correctional clients, and whether this support encourages or discourages reoffending, is an important contribution with implications for effective community corrections and crime prevention strategies (Schaefer, Moir, et al., 2019; Schaefer, Townsley, et al., in press). The current study qualitatively examines these relationships to address this gap in the literature.

\section{Literature Review}

Social support has long been identified as a key element in the management of correctional clients, with criminal justice agencies recognising that the family and friends of these individuals form part of the solution to many crime problems (Schaefer et al., 2019; Solomon et al., 2008). The social networks of prisoners, probationers, and parolees contribute to their loved ones' criminal careers, and play important roles in offending pathways. Interestingly, however, the assumption is often made that individuals deemed as "social supports" are inherently prosocial themselves and serve largely prosocial functions in their interactions with offenders. Yet it is certainly possible that the individuals within a person's social network contributed to the onset of offending in the first instance and are, therefore, more likely to contribute to recidivism rather than desistance. This former association has been studied extensively from a criminological perspective, with scholars examining how peers and families contribute to offending (Sullivan et al., 2019). Less research has examined the role that family and friends play once that individual has been processed through the criminal justice system, is under community correctional supervision, and is aiming to "go straight." Some of this research examines the role of social support during the re-entry process (Bares \& Mowen, 2020; Denney, Tewksbury, \& Jones, 2014), although fewer studies explore the impact of these relationships on probationers and parolees generally. Criminologists and penologists generally consider the potential crime preventive roles that social networks play in a person's aim to desist (Cobbina, Huebner, \& Berg, 2012; Laub \& Sampson, 2001; Maruna, 2001; Warr, 1998; Wright \& Cullen, 2004), often failing to consider how those same individuals may initiate, facilitate, or simply fail to prevent further offending. The current study aims to fill this gap by investigating the roles that are played by individual members of probationers and parolees' social networks, and how their actions are perceived by those under community supervision orders.

In pursuing these research questions, we have organised the literature review into two sections. In the first section, we examine the research that accounts for the role of family and friends in preventing (re)offending. In the second section, we outline the empirical evidence that showcases how these individuals may contribute to (re)offending. 
"Qualitative Criminology"

\section{How Social Networks Prevent Reoffending}

In addition to protecting against the onset of criminal behaviour (Cullen, 1994; Sullivan et al., 2019), social networks are also central for preventing reoffending. Positive relationships with family and friends are often cited as critical for encouraging desistance and supporting an individual's efforts to "go straight" (Macklin, 2013; Maruna, 2001). Accordingly, Solomon and colleagues (2008) propose that social supports be incorporated into probation and parole assessments and community supervision processes. Social capital is critical to the provision of life needs (e.g. providing the social networks necessary for gaining employment; Macklin, 2013; Sampson \& Laub, 1993; Visher, Kachnowski, LaVigne, \& Travis, 2004; Wright \& Cullen, 1994), and these relationships may be more effective than legal constructs on influencing positive and prosocial behaviour in offenders (Schaefer et al., 2019; Williams \& Hawkins, 1986). Social capital is thought to originate in "socially structured relations between individuals, in families and in aggregations of individuals", whereby these relationships "facilitate social action by generating a knowledge and sense of obligation, expectations, trustworthiness, information channels norms and sanctions (Hagan \& McCarthy, 1997, as cited in Farrall, 2004, p. 60). The National Research Council (2008) stipulates that strengthening support networks and increasing pre-existing bonds to family and community is a useful tool for criminal justice practitioners to utilise in their efforts to promote behavioural change, based on the assumption that these social supports may have a better understanding of the individual's thought processes and behavioural patterns. Indeed, research finds that offenders' loved ones may be able to most accurately identify the risk(s) of reoffending due to their pre-existing knowledge around what triggers the individual to offend (Macklin, 2013; Mills \& Codd, 2008; Schaefer et al., 2016). Leveraging this knowledge could be particularly beneficial for community corrections officers.

When considering the ongoing influence of support networks for offending trajectories, it is widely recognised that strong family relationships are critical for increasing motivation to desist (Burnett, 2004), providing emotional support (Maruna, 2001), and for offering the instrumental support necessary for probationers and parolees to meet their concrete life needs (Visher et al., 2004). Relationships are an important contributing factor in the desistance process and marriage is postulated to be a critical "turning point" in the life-course for would-be desisters (Laub \& Sampson, 1993). However, the processes underpinning the decline in criminal activity after marriage may differ, perhaps being related to the increase in social bonds (as suggested by Laub \& Sampson, 1993), or to the effect of marriage on routine activities (National Research Council, 2008; Warr, 1998). Indeed, certain life events can help to signal to others that desistance is occurring, which can contribute to the "knifing off" process (Bushway \& Apel, 2012; Maruna \& Roy, 2007). 
Orrick and colleagues (2011) consider the impact of social support on recidivism by viewing it through a social support theory framework. The authors propose that networks of people or organisations can assist individuals to meet their needs which, therefore, reduces the likelihood of recidivism. They explore the impacts of both public and private levels of support on individual-level recidivism and found that both are required to reduce levels of recidivism (Orrick, Worrall, Morris, Piquero, Bales, \& Wang, 2011). Additionally, social support, particularly in the form of emotional support, is found to not only reduce recidivism (Cochran, 2014), but also to decrease antisocial cognitions such as hostility (Hoschstetler, DeLisi, \& Pratt, 2010). Importantly, improving social capital is critical to increasing motivation and commitment to desist (Macklin, 2013); accordingly, increasing social support should be an integral part of correctional practice, particularly for the effectiveness of community supervision (Macklin, 2013; Solomon et al., 2008).

Incorporating social supports (such as parents) in supervision strategies is vital and considered to be important for successful completion of community corrections orders. Indeed, when supervising officers focus on increasing their clients' perceived level of connection and support (such as through family counselling), the improved family relationships are associated with reduced offending (Null, 2015). Importantly, Null (2015) also examined the significance of the individual's satisfaction with the support they receive; those who considered their support network as a resource to turn to in times of need had higher levels of satisfaction, which is hypothesised to encourage desistance. Additionally, those who perceived their support network as non-critical and nondemanding were less likely to engage in antisocial behaviour. These findings showcase the influence of social support on reoffending outcomes; however, despite calls to incorporate a person's support network in re-entry initiatives and offender supervision strategies (Schaefer, 2018; Schaefer et al., 2016; Solomon et al., 2008), this area of service provision is generally neglected (Denney et al., 2014).

While the positive influence of social supports on desistance and offending trajectories is well-documented, the particulars of this process is not uniform and may vary across different cohorts. Goodson (2018) considered the role of support persons in assisting female probationers' navigation through community supervision requirements and found parents and siblings to be important for female probationers' stability, noting that they provided both emotional and instrumental support, including housing and childcare. It was also reported that over two-thirds of the participants identified their mothers as support people and advised that their parents and partners were the most significant support in terms of offering practical help and advice, consistent with Macklin's (2013) findings. Meanwhile, though marriage is important for desistance in males (Laub \& Sampson, 1993), romantic partners can be destructive for desistance in females (Leverentz, 2006). Indeed, the desistance process appears to be gendered, with positive 
family relationships being most important for female desisters (Rodermond et al., 2016; Traylor, 2014), while antisocial peers are most destructive for the desistance process of males (Cobbina et al., 2012). Yet attempts at categorisation of antisocial or prosocial partners is also complex: Sometimes those with criminal histories and previous drug use can be a positive support, dependent on where they are in their own recovery journey (Leverentz, 2006). Leverentz noted that this relies heavily on the strength of the relationship, and the negative impacts the person may experience if the relationship were to breakdown. Indeed, individuals can engage in the desistance process more fully if they feel that they are now accountable to others, such as to a child or partner, and therefore do not wish to lose the support of these individuals (Null, 2015; Williams \& Schaefer, 2021).

\section{How Social Networks Contribute to Reoffending}

Despite the various ways that social networks provide positive support for correctional clients and desisting individuals, it is also important to consider how these networks may negatively influence offending trajectories. In contrast to what has been discussed in the preceding section, it is also apparent that social networks can contribute to offending behaviour, whether intentionally or inadvertently. Farrington and Welsh (2008) reported that family members' (particularly parents') previous criminal or antisocial behaviour is the strongest factor for predicting offending. They explored this further to identify that poor parental supervision, parental conflict, and disrupted families are contributing factors for intergenerational offending.

Peer influence is also exceptionally influential (Sullivan et al., 2019), perhaps due to differential association and social learning (Akers, 1998). One of the difficulties in social learning perspectives is the effort to disentangle whether people behave criminally through processes of observation and mimicry or whether they self-select into relationships with others who are similar to themselves, thereby creating an "echo chamber" of reinforcement. Gallupe and colleagues (2019) analysed this relationship between peer selection and personal offending. Their results indicate that this relationship is explained by flocking (that is, individuals choosing to befriend people who offend in a similar way), but that they also adjusted their own offending behaviour to more closely mimic that of their peers. They also noted that those who offend at similar levels are more likely than others to become friends in the first instance.

If family and friends play a significant role in relation to the onset of offending behaviour, there is also reason to suspect that they can perpetuate offending behaviour. A meta-synthesis conducted by Martinez and Abrams (2013) analysed the literature surrounding the impacts of social supports on young people's offending. The study 
examined 13 qualitative articles published between 1998 and 2010 to identify themes within this research. The authors found that generally family members provided instrumental support alongside encouragement for these individuals to avoid returning to criminal behaviour; however, they noted family members often had unreasonably high expectations. The youth described some individuals' family support as "suffocating" despite the family simultaneously being a "major pillar of support" (Martinez \& Abrams, 2013, p. 181). These relationships were described as "the ties that bind", noting family tended to offer the most positive support in terms of direction-taking, advice, motivation, and emotional support. Yet at times, the family members' unreasonable expectations led some of the youth into a self-fulfilling prophecy which resulted in their return to criminal activity. This highlights how family support may appear inherently positive, but that such support may be negatively influential. The researchers also described a running theme across the analysed studies, identifying the pivotal differences between family support and peer support. They defined this as individuals having "walked a fine line" with their peers, in that whilst their peers provided a "sense of belonging" they also offered areas of temptation to return to criminal behaviours (Martinez \& Abrams, 2013, p. 177).

Further research has been conducted in relation to peer influence and criminality. Andrews and Bonta (2010) determined that one of the "Big Four" criminogenic needs is antisocial associates, with a strong correlation between the number of criminal peers a person has and the likelihood of recidivism (Wooditch et al., 2014). Boman and colleagues (2018) noted that individuals reported versatility in their offending behaviour which was like that of their peers. Their findings suggest that criminal behaviour can be perpetuated by peer involvement. It is important to consider this when managing probationers and parolees in the community; this factor is dynamic and malleable, therefore the goal should be to reduce associations with antisocial peers and increase associations with prosocial peers (Andrews \& Bonta, 2010; Schaefer et al., 2016).

\section{The Current Study}

Much research has been conducted to determine the influence of social supports on the development of offending and on prison adjustment and re-entry. Much of this research focuses solely on the people within the support network (such as the type of the relationship) and the impacts this has on offending. However, research has largely failed to consider the particular types of support that those within offenders' networks offer (beyond the dichotomous instrumental versus emotional forms of support), and how the provision of such support is perceived by both parties: the person delivering the support and the person receiving the support. 
It is evident that the effect of friends and family on reoffending pathways is variable. Some studies suggest that social networks serve as protective factors and encourage desistance, while some research emphasises the ways that social networks serve as risk factors for further offending. The equivocal evidence would suggest that the effect of social networks on offending trajectories is contingent on contributing contextual factors, such as the nature and strength of the relationships, social orientations, the kinds of support offered, and each individual's motivation to desist or persist. Much of the research reviewed describes the role of family and friends as if they are passive agents that indirectly influence the person's trajectory, when realistically, these individuals have their own agendas and are likely to interact with the individual in more purposive ways that directly influence offending pathways. Further, the way that people perceive the support offered is likely to influence the way that it is responded to, with implications for whether those individuals will continue to draw on their social network. There is much to be learned about how support is offered by social networks and received by probationers and parolees. Accordingly, the current study aims to provide a contribution by addressing this gap. This study examines the attitudes and actions of a sample of community-supervised correctional clients and a member of their social network (a parent, partner, or a peer).

We pose two research questions:

1. What kinds of support do the loved ones of probationers and parolees provide?

2. Is the support provided by members of probationers' and parolees' social networks (parents, partners, peers) interpreted as being helpful or unhelpful for reducing offending behaviour?

\section{Method}

In this study, we examine 31 interview transcripts with probationers and parolees $(n=15)$ and members of their support network $(n=16)$ to explore the support being provided and whether their statements coincide or diverge. The data for this project has been drawn from a larger trial of a novel model of probation and parole performed in a large metropolitan area in Australia. The Triple-S: Social Supports in Supervision framework extends the recent adoption of environmental criminology theories to community corrections practices (Miller, 2012; Schaefer et al., 2016) by examining the use of social supports as crime controllers for the management of probationers and parolees in the community (Schaefer, Moir, et al., 2019; Schaefer, Townsley, et al., in press). Specifically, the trial involved probation and parole staff operating as "super controllers", identifying, recruiting, and training members of their clients' social networks to serve as "offender handlers", "target guardians", and "place managers" (Sampson, Eck, \& Dunham 2010). These individuals were referred to as "PoPPs" (parents/partners/peers of probationers 
and parolees). As part of an evaluation of this trial, interviews were conducted with a sample of probationers and parolees as well as members of their support network. Using interview transcripts obtained from the qualitative evaluation of the Triple-S project, this study aimed to examine the different types of support provided by parents, partners, and peers to the probationers and parolees and whether this support was perceived as being helpful or unhelpful for reducing reoffending.

\section{Procedure}

The Triple-S trial occurred in one probation and parole district office in 2018. Approximately four months following the implementation of the Triple-S model, semistructured interviews were conducted with correctional clients and their social supports. Participants were recruited for the interview process when they reported to their probation and parole officer for their routine case management meeting. If a social support person accompanied the client for the purposes of that meeting, the Case Manager would extend an invitation for the client and their support person to be interviewed at the completion of their supervision meeting. If the individuals expressed interest, they were met individually by a member of the research team and taken to a private room to further discuss the research project, clarify what participation would entail, and obtain informed consent. Researchers explained to participants that the study was independent from the Department of Corrective Services and guaranteed that their interview responses were confidential and would not be reported back to their probation or parole officer. Confidentiality was maintained by providing each participant with a unique identification number (replaced here with pseudonyms). All interviews were audio recorded and later transcribed. Interview length ranged from 7 minutes to 80 minutes, averaging 27 minutes. At the completion of the interviews both the client and support person were provided a $\$ 20$ grocery voucher. Following this, a debrief was conducted with each participant and they were provided with a list of relevant support organisations.

\section{Participants}

Data was collected at the trial site of Triple-S: Social Supports in Supervision. This study uses only those data obtained when both a client and their social support person agreed to be interviewed (to examine whether they diverge or converge in their perspectives). All individuals who reported to their Case Manager during the two-week data collection window were eligible to participate, irrespective of offence, order, or client type. Throughout this period, 48 clients attended their reporting appointments with a social support person. A total of 15 individual clients accepted the invitation to be interviewed, resulting in a response rate of $31.25 \%$. The final dataset for this study consists of 15 probationer/parolee interviews and 16 support person interviews (one offender had two 
social support persons with them). In line with Cresswell (1998), we determined that this sample size was appropriate for a phenomenological study.

Of the social support people interviewed, there were a variety of relationships between the individual and the client, including one father-son relationship, one fatherdaughter relationship, two mother-son relationships, one roommate, one sibling, and nine partners (including seven girlfriends and two boyfriends). The majority of the social supports interviewed were females (68.75\%). These relationships are detailed in greater depth in Table 1.

Table 1: Client Demographics and Social Support Relationship Types

\begin{tabular}{lllrrr}
\hline Pseudonym & Gender & Offence & $\begin{array}{r}\text { Order } \\
\text { Length } \\
\text { (months) }\end{array}$ & $\begin{array}{r}\text { Support } \\
\text { Person } \\
\text { Pseudonym }\end{array}$ & Relationship \\
\hline Adam & M & Sexual assault & 22 & Anne & Son-mother \\
Bill & M & Drugs & 9 & Betty & Partners \\
Charles & M & Burglary & 16 & Chris & Son-father \\
Dave & M & Burglary & 40 & Danielle & Father-daughter \\
Eli & M & Armed robbery & 24 & Emma & Partners \\
Frank & M & Manufacturing drugs & 18 & Fiona & Partners \\
George & M & Breach of bail & 12 & Gary & Roommates \\
Harold & M & Property damage & 11 & Harriet & Son-mother \\
Ingrid & F & Unauthorised entry with intent & 12 & lan & Partners \\
Jack & M & Dangerous driving & 24 & Jill & Partners \\
Karl & M & Burglary & 97 & Karen & Partners \\
Larry & M & Property damage & 18 & Lily & Son-mother \\
Larry & M & Property damage & 18 & Leah & Partners \\
Mark & F & Wounding & 29 & Mary & Partners \\
Noel & M & Stalking & 24 & Nate & Partners \\
Oscar & F & Burglary & 15 & Olivia & Siblings \\
\hline
\end{tabular}

Of the clients interviewed, there were a variety of sentence lengths and order types which they were subject to. Four participants were subject to Board Ordered Parole, five were subject to Court Ordered Parole and a further six were subject to Probation Orders. The length of orders varied significantly, with some individuals serving nine-month orders, in contrast to one individual serving a 97-month order; the average sentence length was 25.71 months ( $S D=22$ months). Reporting frequencies varied for these individuals, dependent on the agency's standardised risk of reoffending tool, level of service, and phase of the order. Within this sample, the clients' level of service includes standard $(n=3)$, enhanced $(n=9)$, and intensive $(n=3)$, with corresponding reporting frequencies of weekly $(n=3)$, fortnightly $(n=4)$, monthly $(n=6)$, two-monthly $(n=1)$ and four-monthly $(n=1)$. There was also a wide range of offence types within the sample, including individuals sentenced for sexual assault, drug offences, burglary, armed robbery, breach of bail, 
unauthorized entry with intent, dangerous driving, wounding, and stalking. There was considerable variation in the length of criminal history for those within the sample. There were five individuals serving their first order in the state, while others had been subject to a variety of orders previously ( $\mathrm{Max}=9, \mathrm{M}=2.53, \mathrm{SD}=2.03$ ).

\section{Materials}

Semi-structured interviews with the clients' social support people focused on the following domains: relationship with the probationer/parolee, overall experience with Corrective Services, involvement in the client's supervision order, their level of involvement in the individual's life, understanding of the person's involvement in crime, their efforts to stay out of trouble, and their goals and anticipated achievements for the future (Schaefer et al., 2019). The semi-structured client interviews focused on the type of order they were subject to, their correctional history, their expectations of Corrective Services, their experiences on the current order thus far, their support people, their day-to-day life, and plans for the future.

\section{Analyses}

The data were approached inductively through a reflexive thematic analysis. Braun and Clarke (2006) discuss the benefits of thematic analysis due to its theoretical freedom and flexibility. Analyses were conducted following five steps, initially presented by Braun and Clarke (2006) and later clarified by the authors (2020). First, all transcripts were read through several times by a single coder to become familiar with the data. Second, focused reading of the transcripts identified initial codes. The third step involved assigning codes to themes in relation to each of the research questions and developing a list of dominant themes. Fourth, using excerpts from the data, the themes were collaboratively reviewed and validated against the data. Finally, themes were named, refined, and defined.

\section{Results}

This qualitative study explores two central research questions. The first research question asks about the kinds of support provided by the loved ones of probationers and parolees, while the second poses the query as to whether this support is perceived as helpful, or unhelpful for reducing reoffending. Through a thematic analysis, eight forms of support were identified. As the study does not measure recidivism, the themes identified are categorised below according to an evaluation of whether they are more likely to have a positive effect and discourage reoffending or a negative effect and encourage reoffending (based on the available empirical evidence about risk and protective factors). We further describe how the support from PoPPs was perceived by the clients. 


\section{Positive Support Which May Discourage Reoffending}

Our analysis of the data revealed five forms of support provided by the family and friends of probationers and parolees that are postulated to discourage reoffending: emotional support, identification of risk factors, being present, being future-focused and goalorientated, and instilling consequential thinking.

\section{Providing Emotional Support}

Emotional support appears to be one of the most prominent forms of support provided by community correctional clients' social supports and was identified in 11 of the 16 interviews (68.75\%) with support people. Emotional support is characterised by the willingness of social supports to engage in conversation with the individuals about their respective feelings and to display to their loved one that they are present and remain alongside them throughout their correctional experience. One client noted that the main support he receives from his family is "never-ending compassion and love" (Adam), with his mother stating, "I offer him my opinion and my advice. Then he talks to me about how he's feeling" Anne). Emotional support also appeared frequently within romantic relationships. One client discussed the support and dedication shown by his girlfriend during his custodial sentence stating, "We're still getting through it, but we're going through it together. I think that's the main thing. I think it's easier for me-someone like me, and her, to go through it together" (Frank). His partner echoed these sentiments; "Yes, he was in there [prison] ... but I was right there along with him, doing it as well" (Fiona). Another intimate partner highlights the significance of providing their loved one with an outlet to offload, stating that his role was to "mainly just be there when she needs someone to talk to and just be around when she's feeling depressed and really down" (Ian). The client noted that her partner "calms me down" by "just getting me to do other things or just talk to me" (Ingrid). A girlfriend of another client described how she calms her partner down, holds him, and reassures him that everything is going to be okay (Karen).

Articulating positive affirmations was identified as an important way for social supports to provide their loved one with emotional support. Positive affirmations are statements that encourage positive outcomes by instilling confidence and ambition in the recipient. While they tended to be reflections of current behaviour (for example, commending the probationer/parolee for their existing efforts), they are geared toward encouraging ideal future behaviours. When talking about her son, one mother stated, "He needs to be encouraged. I suppose people need to tell him that he's doing well, he needs praise" (Anne). Similarly, one romantic partner stated that she "just keep letting him know he's doing a good job. Just keep encouraging him to do the right thing" (Karen). 
Importantly, another intimate partner highlighted how it is important for correctional clients to feel that someone has belief in them, perhaps when self-belief is lacking; she stated, "having someone there that just believes in him and tells him that they're proud of him. I think it's really important ... it's that nurturing" (Betty).

\section{Identifying Risk Factors}

Identifying risk factors for offending was a common theme for how support people supported their loved ones to go straight. Both familial and romantic support people utilised this support strategy; however, it appeared more frequently in familial relationships. One client's daughter was able to identify that when her father "runs into people" he "starts back on it [drugs]" (Chris). The same daughter also recognised that participating in social media was a significant contributing factor to her father's return to substance abuse. Further highlighting some of the ways support people take proactive steps to intervene and prevent reoffending, the mother of one offender described how she conducts checks on her son, asking, "you're on Facebook ... who are you talking to? What are you doing?" (Anne). A number of support people, mostly romantic partners, recognised the criminogenic effect of antisocial peers and described some of the ways they have purposely helped their loved one to cut ties with specific social groups. One participant described the restructuring of their social circle to ensure their loved one does "not to go back to old people. We only have decent people in our lives" (Karen). Likewise, one romantic partner stated, "we're taking a step back and we're not getting involved. But [we've] actually moved away from that area" (Leah).

\section{Being Present and Available}

Many social supports discussed the importance of simply being present for their loved one. In practice this included providing transport to appointments (Chris), being available to attend community supervision meetings (Chris), chauffeuring to enable social interaction (Gary), and being available to listen when required (Ian). One social support described how he did not go to work on occasion to transport his son to places he needs to go (Chris). Other supports noted "I'm doing all the running around for his-health wise and mental health as well because he also sees a psychologist" (Harriet). One intimate partner described how she attended treatment sessions with her loved one, " ... it's going to be me and him, and that one person, because he can't handle being in groups" (Leah). The brother of one client stated how he provides support by "just being around helping her with little things like coffee and milk ... just like a normal person, just watch TV and just relax, have a coffee and talk" (Olivia). 


\section{Being Future-Focused and Goal-Oriented}

Social support people often demonstrated their support by assisting loved ones to plan for and achieve future goals. By being future-focused, social supports communicated opportunities to clients and helped to create a vision of what the individual could achieve and ways they could achieve it. One intimate partner (Betty) described how she supports her partner to work towards the future they desire, including gaining custody of their children and living as a family. Another social support stated how she is supportive of her partner's goals and encourages him to set new goals (Emma), highlighting the significance of goal orientation for forging new pathways. Importantly, one intimate partner described the significance of goal sharing, stating,

I think we bounce off each other, so I think if I wanted to-for example ... [go] back and run amok and get up to no good, I think that he would too, so I think that me staying positive and me continuing to do the right thing and having the same goals as him and having that desire to have a decent life-I think that that bounces off him ... us both wanting the same goals, that makes it 1000 times better and yeah, because we can both see the big picture and we both want that, so it makes it more worthwhile .(Fiona)

It is notable that many clients and their support people identified conventional goals that they hope to achieve. One intimate partner described a prosocial vision for her partner and their future; when asked what she hopes for the future she stated, "get a job; hopefully for her sake the kids come home which is going to make it a lot easier for her; then just better our lives; hopefully one day buy a house; keep out of trouble" (Ian). Another romantic partner explained that they are expecting a child and discussed plans to "get a house soon ... he's hoping to get a job soon ... [and] have a roof over our heads" (Leah). Likewise, one intimate partner indicated that after his partner completes her correctional order they plan to buy a house, get married and focus on the future, stating "we just don't want to look back, just keep looking forward—moving forward in life" (Mary). Conventional goals were described mostly by intimate partners as opposed to family members, however, one client's mother expressed how she just wants her son to have a "good life and keep moving forward like he is" (Anne).

Instilling Consequential Thinking

The last form of support identified in the data involved support people encouraging consequential thinking. Instilling the notion of consequences into probationers and parolees' thought processes was a way several support people tried to steer their loved ones in the right direction. One father discussed his attempts, saying "you've got to sit 
down and talk with him and try and talk him out of going to do it. You say, 'you know it's wrong, you're going to end up back in jail'" (Chris). Similarly, one intimate partner described how she had "always been a voice of reason for him" and how "I'm like, 'no, you don't-it's not worth it and this and that' ... He's never actually had to think about the pros and cons of doing something. Stealing something or doing this or doing that ... he's stopping in his thinking for the first time ever and he is trying really hard" (Betty). Finally, another partner explained how she anticipates her loved one's behaviour and makes similar attempts to highlight the potential for negative outcomes, stating, "normally he would have reacted and gone and dealt with it. But I'm like, 'look, you go and do that, you're going to get into trouble ... I go, 'well if you go do that, you're going to get locked up again'. So I put the cards on the table pretty much" (Emma).

\section{How These Forms of Support May Discourage Reoffending}

The themes described above each work independently to discourage reoffending. The themes offered above are a combination of both instrumental support, such as being present and available for concrete life needs and the identification of risks, as well as emotional support, which includes being willing to discuss feelings with the offender and to offer support and strategies to cope with life stressors. As evidenced by the literature, both of these types of support have positive outcomes for individuals, particularly if the person perceives this support as positive (Graffam \& Shinkfield, 2012; Maruna, 2001; Naser \& LaVigne, 2006; Pleggenkuhle, Huebner, \& Kras, 2016; Schaefer et al., 2019). Strong family support in particular is associated with improved outcomes for (ex)offenders (Nelson, Dees, \& Allen, 2011), with individuals with close family ties reporting higher levels of optimism and willingness to desist (Burnett, 2004). Social networks can be major pillars of support for actively desisting individuals, and our data suggests that they can be utilised within community supervision to identify risks that should be avoided, keep offenders on the right track, provide a sense of accountability and a sense of future focus, and can deliver emotional support and advice which is expected to discourage reoffending.

\section{Negative Support Which May Encourage Reoffending}

Through our thematic analysis of the transcripts, we identified three forms of support provided by the family and friends of the probationers and parolees that we speculate will encourage reoffending: the deprivation of something meaningful, the use of avoidance and distraction methods, and employing fear tactics. 
Deprivation of Something Meaningful

Depriving a loved one of something meaningful was identified as a theme which was specific to the familial relationships. This involved the social support person threatening to take something away from the individual which they believed would have a significant impact on the person's behaviour, and ultimately it appeared the social support believed this would ensure the individual does not reoffend. Within the father-daughter relationship, the social support (daughter) made several threats, "if you're straight to the point, firm, 'you're not seeing the kids', 'get back on the road"' (Danielle). This social support also made reference to not allowing her father to see her children whilst he was using illicit substances-"until you're back on the road then that's when you're going to be seeing the grandchildren because I cannot and I will not have that around my children." A mother also referred to not allowing her son to live with her if he wasn't a different person to what he was previously (Anne).

\section{Use of Avoidance and Distraction Methods}

Avoidance methods were identified and involved social supports making attempts to engage the individual in activities to distract them from previous criminal thinking, criminal behaviour, or criminal associates. Examples of this were dominant within familial relationships. A father noted, "hopefully get him into something that he likes and for him to take up hobbies or something and try and get his mind away from all of the other stuff" (Chris). A mother discussed similar tactics to keep her son away from antisocial behaviour, stating, "When he gets really bored and has nothing to do he will go and do whatever he damn well pleases. So, we've been keeping that at bay and just every weekend doing something, or we've just started walking every afternoon" (Danielle).

\section{Employing Fear Tactics}

Fear tactics were identified as statements which appeared threatening and seemed to be utilised to "scare" individuals away from offending behaviour. A clear example of this is "you're going [to] end up in jail, you've got to stay away from it" (Chris). Similar statements included "well if you go do that, you're going to get locked up again" (Emma). Fear tactics were also identified in the father-daughter relationship, with the client's loved one stating, "I told dad-I said, 'if you do anything I will be ringing them [parole]', and he goes, 'are you going to dob me in', and I said, 'I don't care if it's going to dob you in to be honest'" (Danielle). This particular social support also outrightly referenced scaring her father, stating, "Well if you can't learn your lesson from already being in jail then there's something that's got to be big around here, and if it's your daughter scaring you then that's what it's got to be" (Danielle). 
How These Forms of Support May Encourage Reoffending

While it is indisputable that the social support persons we interviewed were wellintentioned in their actions, some of their choices regarding their interactions with the probationers and parolees under supervision may inadvertently enable reoffending. The deprivation of something meaningful may encourage reoffending or relapse due to the negative perspective the client may take toward this action. The bond of these somewhat tenuous relationships could be threatened by the social support depriving the offender of something the individual places in high regard (Leverentz, 2006). Although the use of avoidance or distraction may appear beneficial initially, these strategies are not maintainable in the long-term (Williams \& Schaefer, 2021). It puts the person in a place that they are consistently avoiding issues, such as substance abuse or emotional triggers, rather than directly dealing with the corresponding risks. The use of fear tactics may produce a divide or disconnect within the relationships, and the strength of the relationship (particularly how the offender values the opinions of their loved one) can influence the effectiveness of this strategy (Worrall, Els, Piquero, \& TenEyck, 2014). It may also be that statements such as "you're going to get locked up again" may instil a self-fulfilling prophecy or a defiant reaction (Sherman, 1993).

\section{Perceptions of These Supports}

As our interview participants were granted confidentiality, we do not have follow-up data for each probationer and parolee regarding their reoffending outcomes. However, we did ask each client how they perceived the support they received from their PoPP. Specifically, probationers and parolees were asked, "Has the behaviour of your support person changed recently/since their involvement in your supervision order? Is this a good thing or a bad thing?" Our findings showed that, generally, the clients reported the support of their loved ones as beneficial and positive for them; however, many of our participants experienced difficulty in articulating or specifying what it was about the support that they received that they believed was having a positive effect.

One client (Charles) discussed the support he receives from his father, describing the financial support by providing him money each week, assisting him through his presence, being available to take him to appointments, and what he described as his father giving him "lectures." The individual discussed that his father also supports him emotionally, stating that "If I ever struggle, I can always tell him, and he'll give me a lecture." While this seemed negative on the surface, when probed, the client concluded these "lectures" are beneficial in the long run, because he'll say "just stop dad, I won't do it. So, then I don't have to hear the lecture." He further reported that his dad "keeps me honest", and how he "gave me a lecture about the junkies in the waiting room before." 
Collectively, this client expressed how his father and girlfriend are immensely supportive, primarily because "they're the people that are around when probation and parole aren't." Several of our interview participants communicated similar sentiments, feeling that their support person "has my best interests" (Dave) and "loves me unconditionally" (Oscar). Yet $100 \%$ of these 15 clients failed to explicitly categorise the support received by their PoPP as good or bad, instead explaining that they do feel supported, but that these support strategies feel more or less useful depending on the circumstances. Interestingly, some clients cited only the elements of emotional support they received from their loved one, while their loved one highlighted several punishment-oriented or fear-related tactics that they use. The PoPPs were more likely to describe these strategies (e.g. moulding routines and altering environments, reshaping social circles, trigger identification and avoidance) as being useful for changing the decision-making and criminal conduct of their loved one through the alteration of routine activities and reducing exposure to criminogenic settings or people (Schaefer et al., 2019). Thus, while there may be logic to what the social supports were aiming to do, these tactics do not appear to be wellreceived by the probationers and parolees themselves.

\section{Discussion}

The role of social support has long been utilised as an element in the management of correctional clients. However, there is a debate within the literature: Some evidence suggests that these supports are beneficial in helping individuals to desist (Burnett, 2004; Macklin, 2013; Maruna, 2001; National Research Council, 2008; Orrick et al., 2011; Visher et al., 2004), while other studies show that those within the social support network can be a contributing factor to the person's onset and continuation of offending behaviour (Farrington \& Welsh, 2008; Gallupe et al., 2019; Martinez \& Abrams, 2013). Unfortunately, there is minimal evidence about the shape of these interactions between corrections clients and their social support networks during community supervision orders. The current study helps to address this gap and highlights some of the complexities within clients' social networks and how these may or may not contribute to reoffending.

\section{Types of Support Provided}

The first research question examined the types of support provided by members of probationers and parolees' social networks. Analyses identified eight themes related to the types of social support provided to clients including the provision of emotional support, identification of risk factors, being present and available, being future-focused and goalorientated, instilling consequential thinking, the deprivation of something meaningful, using avoidance and distraction methods, and employing fear tactics. Some of these 
strategies are consistent with the findings of other studies (Hoschstetler et al., 2010; Macklin, 2013; Gallupe et al., 2019) which suggest that social supports can provide influence which may either encourage or discourage reoffending. Social support persons appeared to have had positive intentions regarding the support they provided, but some were not confident about their ability to influence their loved one's behaviour. Some social supports believed their loved ones were desisting as a result of being "tired of the revolving door" (Fiona), attributing limited importance to their own influence as they "can't tell him what to do" (Anne). Yet, evidence suggests that social support can have an important influence on a client's behaviour (Naser \& LaVigne, 2006; Solomon et al., 2008) when appropriate strategies are utilised (Schaefer et al., 2019).

\section{The Potential Impact of Social Supports on Reoffending}

The second research question explored whether the support provided to probationers and parolees by their social networks may potentially be encouraging or discouraging of further offending behaviour. Findings were mixed, with our analyses suggesting that social supports can be both positive and/or negative influences regarding reoffending. Although we did not have recidivism data for the individual interview participants, we categorised the social support strategies used by PoPPS as either likely to limit reoffending risk or to inadvertently exacerbate it. These categorisations were premised on the extant literature about effective practices in correctional supervision, crime prevention, and desistance. Namely, we hypothesised that those practices that utilised components of the principles of effective correctional intervention, core correctional practices, cognitive-behavioural techniques, and strengths-based approaches were more likely to dissuade further criminal conduct (e.g. RNR, STARR, EPICS, STICS; Andrews \& Bonta, 2010; Bonta et al., 2010; Dowden \& Andrews, 2004; Kennealy et al., 2012; Lipsey, Landenberger, \& Wilson, 2007; Lowenkamp, Holsinger, Robinson, \& Alexander, 2012; Smith, Schweitzer, Labrecque, \& Latessa, 2012). Conversely, we estimated that the tactics which emphasised deterrence or a punishment orientation may have (at worst) aggravated criminal decision-making or (at best) eft criminogenic needs untouched (Cullen \& Jonson, 2012; MacKenzie, 2006; Schaefer et al., 2016).

Family relationships in particular seemed to utilise support strategies that could inadvertently encourage reoffending (or may fail to prevent reoffending). Consistent with Martinez and Abrams (2013), we speculate that some of the parental pressure felt by clients may be too overwhelming and was at times perceived as unsupportive from the individual's perspective. Parental relationships, despite positive intentions, could be harsh on the probationer or parolee and apply unrealistic expectations. Some family members threatened to remove themselves as a support for the person entirely should (s)he fail in some way (e.g. a return to drug use, a breached parole order, a new offence). Although 
the support persons likely believed that they were helping to stimulate positive and compliant behaviour from their loved one, these standards may have the unintended consequence of weakening these social bonds, creating self-fulfilling prophecies, or producing defiant reactions, each of which could inadvertently lead to reoffending. Alternatively, intimate partners seemed more likely to offer support that is considered to positively influence an individual's behaviour to not reoffend. Our analyses suggest that romantic partners are more dependent on their other half engaging in prosocial behaviour due to their own expectations of what they want their relationship to look like in the future. Additionally, these partnerships resulted in co-habitation more often than some of the familial relationships, which can assist with monitoring and regulation of routine activities (Schaefer et al., 2019). Accordingly, romantic partners seemed more greatly invested in their loved one completing their order successfully and desisting.

\section{Limitations and Directions for Future Research}

Despite the significance of these findings, this study is not without its limitations. While efforts were made to ensure the sample was representative of the population reporting to the community corrections office, the small sample size limits the generalisability of findings. Further, as the current study utilises only self-reported data, the data may include some biases or inaccuracies. Finally, while all attempts were made by the research team to ensure confidentiality and anonymity throughout data collection, it is acknowledged that some participant responses may have been influenced by the setting within which they were interviewed and a potential desire to create a positive impression for the research team or the agency. In addition to addressing the above limitations, future research could build on the results of the current study and test the efficacy of each form of support by utilising reoffence data to identify which types of support are objectively correlated with recidivism and desistance.

Notwithstanding these limitations, our study is unique in that both the probationer or parolee and their support person were interviewed about their experiences relating to the provision of support. To the best of our knowledge, it is also one of the first studies to focus on a community-supervised correctional population in the empirical examination of social support, discovering ways in which these support persons help correctional clients navigate their supervision orders. Findings show that these relationships should not be assumed to be universally prosocial or protective in their impact; some social support persons use inappropriate techniques that, at best, are perceived as unhelpful by the client, and at worst, may unintentionally exacerbate or encourage offending behaviour (see Schaefer, Moir, et al., 2019; Schaefer, Townsley, et al., in press). Consequently, scholars should continue to investigate these relationships in order to develop best practices for utilising support networks in the community supervision of correctional 
clients, with the aim of providing probationers and parolees with the most favourable conditions to encourage their desistance from crime.

As part of the larger evaluation of the Triple-S trial (see Schaefer et al., in press), the research team discovered that not all correctional clients had support persons in their lives who could serve as prosocial PoPPs. While nearly one-third of the probationers and parolees at the trial site had a PoPP participate in the supervision order in some way (typically an office visit for a routine case management meeting), some clients were not able to identify members of their social networks who they felt would be supportive of the goals of a community corrections order. More generally, we found that many of the probationers and parolees were able to identify ample numbers of people in their social networks who they believed would be supportive. Problematically, however, many of these individuals were either antisocial influences themselves (such as co-offenders, gang members, or substance abusers) or were unable to be involved in the project (such as minor children or family that lived far away). Although there is ample empirical evidence indicating that the social supports of correctional clients serve crime reduction purposes, it is also sensible that these social networks can also be absent or criminogenic (Denney, et al., Martinez \& Abrams, 2013; United Nations, 2018)—if these conditions served a role in promoting propensity or opportunity previously, it may not be sensible to expect that these circumstances would easily change. Accordingly, correctional interventions that emphasise the role of social supports in encouraging desistance may need to first recruit prosocial individuals that fundamentally alter the routine activities of probationers and parolees.

\section{Implications}

The results of this study have significant implications for community corrections practices. Our findings suggest that the utility of opportunity-reduction approaches to probation and parole supervision (which apply environmental criminology theories to community corrections practices; Miller, 2012; Schaefer et al., 2016) may be complicated rather than universally aided through the addition of social supports that serve in crime prevention roles (Schaefer, Moir, et al., 2019; Schaefer, Townsley, et al., in press). There is little available research that examines the relationship between social supports and corrections clients under community supervision, with our project providing important insights into the social support provided by members of probationers and parolees' networks and the possible ramifications these varying forms of support may have for subsequent offending. Consistent with the available evidence, the current study finds that social supports may provide both a positive and a negative influence on clients' behaviour (Gallupe et al, 2019; Hoschstetler et al., 2010; Macklin, 2013; Schaefer et al., 2019). Our findings do lend support to the notion that members of an individual's social network may 
be invested in solutions. One of the ways we believe this was evidenced in the current study is that romantic partners seemed more determined to co-produce the client's desistance.

Accordingly, if probation and parole officers utilise probationers and parolees' social supports to enhance supervision practices, there should be a particular focus on relationships where the support person has a personal investment in the client doing well. Despite best intentions, some of the support people interviewed may have unintentionally created criminogenic circumstances, particularly in relation to the pressure exerted on individuals in relation to unrealistic expectations (Martinez \& Abrams, 2013). Therefore, community supervision officers should take precautions when utilising social supports, educating these individuals about the potential impacts of their behaviours on their loved ones and teaching positive and prosocial ways they can support their loved one to avoid reoffending.

\section{References}

Akers, R. L. (1998). Social learning and social structure: A general theory of crime and deviance. Boston: Northeastern University Press.

Andrews, D. A., \& Bonta, J. (2010). The psychology of criminal conduct ( $5^{\text {th }}$ ed.). New York: Taylor \& Francis.

Bares, K. J., \& Mowen, T. J. (2020). Examining the parole officer as a mechanism of social support during reentry from prison. Crime \& Delinquency, 66(6-7), 1023-1051.

Boman, J. H., Mowen, T. J., \& Higgins, G. E. (2018). Social learning, self-control and offending specialization and versatility among friends. American Journal of Criminal Justice, 44(1), 3-22.

Bonta, J., Bourgon, G., Rugge, T., Scott, T. L., Yessine, A.K., Gutierrez, L., \& Li, J. (2010). The Strategic Training Initiative in Community Supervision: Risk-Need-Responsivity in the Real World. Ottawa, Canada: Public Safety Canada.

Braun, V., \& Clarke, V. (2006). Using thematic analysis in psychology. Qualitative Research in Psychology, 3(2), 77-101.

Braun, V., \& Clarke, V. (2020). One size fits all? What counts as quality practice in (reflexive) thematic analysis? Qualitative Research in Psychology. 
Burnett, R. (2004). To reoffend or not to reoffend? The ambivalence of convicted property offenders. In S. Maruna \& R. Immarigeon (Eds.), After crime and punishment: Pathways to offender reintegration (pp. 153-180). Cullompton, Devon: Willan.

Bushway, S. D., \& Apel, R. (2012). A signaling perspective on employment-based reentry programming: Training completion as a desistance signal. Criminology \& Public Policy, 11(1), 21-50.

Cobbina, J. E., Huebner, B. M., \& Berg, M. T. (2012). Men, women, and postrelease offending. Crime \& Delinquency, 58(3), 331-361.

Cochran, J. C. (2014). Breaches in the wall: Imprisonment, social support, and recidivism. Journal of Research in Crime and Delinquency, 51(2), 200-229.

Creswell, J. W. (1998). Qualitative inquiry and research design: Choosing among five traditions. Thousand Oaks, CA: Sage Publications.

Cullen, F. T. (1994). Social support as an organizing concept for criminology: Presidential address to the Academy of Criminal Justice Sciences. Justice Quarterly, 11(4), 527-559.

Cullen, F. T., \& Jonson, C. L. (2012). Correctional theory: Context and consequences. Thousand Oaks, CA: Sage.

Denney, A. S., Tewskbury, R., \& Jones, R. S. (2014). Beyond basic needs: Social support and structure for successful offender reentry. Journal of Qualitative Criminal Justice \& Criminology, 2(1), 39-67.

Dowden, C., \& Andrews, D. A. (2004). The importance of staff practice in delivering effective correctional treatment: A meta-analytic review of core correctional practice. International Journal of Offender Therapy and Comparative Criminology, 48(2), 203-214.

Duwe, G. (2018). The importance of the company you keep: The effectiveness of social support interventions for prisoners. Washington, DC: American Enterprise Institute.

Executive Session on Community Corrections. (2017). Toward an approach to community corrections for the 21st century. Cambridge, MA: Harvard Kennedy School.

Farrall, S. (2004). Social capital and offender reintegration: Making probation desistance focused. In S. Maruna \& R. Immaigeon (Eds.), After crime and punishment: Pathways to offender reintegration (pp. 57-82). London: Wilan. 
Farrington, D. P., \& Welsh, B. C. (2008). Saving children from a life of crime. New York: Oxford University Press.

Gallupe, O., McLevey, J., \& Brown, S. (2019). Selection and influence: A meta-analysis of the association between peer and personal offending. Journal of Quantitative Criminology, 35(2), 313-335.

Goodson, M. V. (2018). Help or hindrance: Female probationers' navigation of supervision requirement through personal support networks. Criminal Justice and Behavior, 45(10), 1483-1506.

Graffam, J., \& Shinkfield, A. J. (2012). The life conditions of Australian ex-prisoners: An analysis of intrapersonal, subsistence, and support conditions. International Journal of Offender Therapy and Comparative Criminology, 56(6), 897-916.

Hochstetler, A., DeLisi, M., \& Pratt, T. C. (2010). Social support and feelings of hostility among released inmates. Crime \& Delinquency, 56(4), 588-607.

Jiang, S., Fisher-Giorlando, M., \& Mo, L. (2005). Social support and inmate rule violations: A multilevel analysis. American Journal of Criminal Justice, 30(1), 71-86.

Jiang, S. L., \& Winfree, T. (2006). Social support, gender, and inmate adjustment to prison life: Insights from a national sample. The Prison Journal, 86(1), 32-55.

Kennealy, P., Skeem, J. L., Manchak, S. M., \& Eno Louden, J. (2012). Offender-officer relationships matter: Firm, fair and caring officer-offender relationships protect against supervision failure. Law and Human Behavior, 36(6), 496-505.

Laub, J. H., \& Sampson, R. J. (1993). Turning points in the life course: Why change matters to the study of crime. Criminology, 31(3), 301-325.

Laub, J. H., \& Sampson, R. J. (2001). Understanding desistance from crime. Crime and Justice, 28, 1-69.

Leverentz, A. M. (2006). The love of a good man? Romantic relationships as a source of support or hindrance for female ex-offenders. Journal of Research in Crime and Delinquency, 43(4), 459-488.

Lipsey, M. W., Landenberger, N. A., \& Wilson, S. J. (2007). Effects of cognitive-behavioral programs for criminal offenders. Campbell Systematic Reviews, 3(1), 1-27. 
Lowenkamp, C. T., Holsinger, A., Robinson, C. R., \& Alexander, M. (2012). Diminishing or durable treatment effects of STARR? A research note on 24-month re-arrest rates. Journal of Crime and Justice, 37(2), 275-283.

MacKenzie, D. L. (2006). What works in corrections: Reducing the criminal activities of offenders and delinquents. New York: Cambridge University Press.

Macklin, A. (2013). Community management of offenders: The interaction of social support and risk. Federal Probation, 77(1), 17-21.

Martinez, D J., \& Abrams, L. S. (2013). Informal social support among returning young offenders: A metasynthesis of the literature. International Journal of Offender Therapy and Comparative Criminology, 57(2), 169-190.

Maruna, S. (2001). Making good: How ex-convicts reform and rebuild their lives. Washington, DC: American Psychological Association.

Maruna, S., \& Roy, K. (2007). Amputation or reconstruction? Notes on the concept of "knifing off" and desistance from crime. Journal of Contemporary Criminal Justice, 23(1), 104-124.

Miller, J. (2012). Probation supervision and the control of crime opportunities: An empirical assessment. Crime and Delinquency, 60(8), 1235-1257.

Mills, A., and Codd, H. (2008). Prisoners' families and offender management: Mobilizing social capital. The Journal of Community and Criminal Justice, 55(1), 9-24.

Naser, R. L., \& LaVigne, N. G. (2006). Family support in the prisoner reentry process. Journal of Offender Rehabilitation, 43(1), 93-106.

National Research Council. (2008). Parole, desistance from crime, and community integration. Washington, DC: The National Academies Press.

Nelson, M., Dees, P., \& Allen, C. (2011). The first month out: Post incarceration experiences in New York City. Federal Sentencing Reporter, 24, 72-75.

Null, C. R. (2015). Actual and perceived social supports of offenders under community supervision (unpublished doctoral dissertation). University of California, Irvine. 
Orrick, E. A., Worrall, J. L., Morris, R. G., Piquero, A. R., Bales, W. D., \& Wang, X. (2011). Testing social support theory: A multilevel analysis of recidivism. Journal of Criminal Justice, 39(6), 499-508.

Pleggenkuhle, B., Huebner, B. M., \& Kras, K. R. (2016). Solid start: Supportive housing, social support, and reentry transitions. Journal of Crime and Justice, 39(3), 380-397.

Rodermond, E., Kruttschnitt, C., Slotboom, A., \& Bijleveld, C. (2016). Female desistance: A review of the literature. European Journal of Criminology, 13(1), 3-28.

Sampson, R., Eck, J. E., \& Dunham, J. (2010). Super controllers and crime prevention: A routine activity explanation of crime prevention success and failure. Security Journal, 23(1), 37-51.

Sampson, R. J., \& Laub, J. H. (1993). Crime in the making: Pathways and turning points through life. Cambridge, MA: Harvard University Press.

Schaefer, L. (2018). Correcting the "correctional" component of the corrections officer role: How offender custodians can contribute to rehabilitation and reintegration. Corrections: Policy, Practice and Research, 3(1), 38-55.

Schaefer, L., Cullen, F. T., \& Eck, J. E. (2016). Environmental corrections: A new paradigm for supervising offenders in the community. Los Angeles: Sage.

Schaefer, L., Moir, E., \& Williams, G. (2019). When a loved one is on community supervision: The crime controller strategies used by "PoPPs" (parents / partners / peers of probationers and parolees). Criminal Justice Studies, 32(2), 81-98.

Schaefer, L., Townsley, M., \& Hutchins, B. (in press). Does the involvement of family and friends improve probation and parole outcomes? A quantitative evaluation of Triple-S: Social Supports in Supervision. Trends \& Issues in Crime and Criminal Justice.

Sherman, L. W. (1993). Defiance, deterrence, and irrelevance: A theory of the criminal sanction. Journal of Research in Crime and Delinquency, 30(4), 445-473.

Solomon, A. L., Osborne, J., Winterfield, L., Elderbroom, B., Burke, P., Stroker, R., Rhine, E., \& Burrell, W. (2008). Putting public safety first: 13 parole supervision strategies to enhance reentry outcomes. Washington, DC: Urban Institute. 
Smith, P., Schweitzer, M., Labrecque, R. M., \& Latessa, E. J. (2012). Improving probation officers' supervision skills: an evaluation of the EPICS model. Journal of Crime and Justice, 35(2), 189-199.

Sullivan, C. J., Childs, K. K., \& Gann, S. (2019). Peer influences on offending. In D. P. Farrington, L. Kazemian, \& A. R. Piquero (Eds.), The Oxford Handbook of Developmental and Life-Course Criminology (pp. 404-431). New York: Oxford University Press.

Traylor, L. (2014). The social organization of motherhood and mothering for formerly incarcerated black women (unpublished doctoral dissertation). University of Illinois, Chicago.

United Nations. (2018). Introductory handbook on the prevention of recidivism and the social reintegration of offenders. Vienna: United Nations.

Valera, P., Brotzman, L., Wilson, W., \& Reid, A. (2017). "It's hard to reenter when you've been locked out": Keys to offender reintegration. Journal of Offender Rehabilitation, 56(6), 412-431.

Visher, C., Kachnowski, V., LaVigne, N., \& Travis, J. (2004). Baltimore prisoners' experiences returning home. Washington, DC: Urban Institute.

Warr, M. (1998). Life-course transitions and desistance from crime. Criminology, 36(2), 183-216.

Williams, K. R., \& Hawkins, R. (1986). Perceptual research on general deterrence: A critical review. Law and Society Review, 20(4), 545-572.

Williams, G. C., \& Schaefer, L. (2021). Expanding desistance theory through the integration of offender strategies. Journal of Crime and Justice, 44(1), 16-32.

Wooditch, A., Tang, L. L., \& Taxman, F. S. (2014). Which criminogenic needs are most important in promoting desistance from crime and substance use? Criminal Justice and Behavior, 41(3), 276-299.

Worrall, J. L., Els, N., Piquero, A. R., \& TenEyck, M. (2014). The moderating effects of informal social control in the sanctions-compliance nexus. American Journal of Criminal Justice, 39(2), 341-357. 
"Qualitative Criminology"

Wright, J. P., \& Cullen, F. T. (2004). Employment, peers, and life-course transitions. Justice Quarterly, 21(1), 183-205.

\section{Contributors}

Lacey Schaefer is a Senior Lecturer in the School of Criminology and Criminal Justice at Griffith University and a Research Fellow with the Griffith Criminology Institute. She holds research expertise in criminological theory and correctional ideologies and interventions. As an applied researcher, Dr Schaefer trains community corrections agencies in client supervision strategies and rehabilitation programs.

Gemma C. Williams is a PhD candidate in the School of Criminology and Criminal Justice at Griffith University. Her doctoral thesis uses a matched pair longitudinal design to examine how prisoners' expectations of re-entry correspond with their actual re-entry experiences. Her research interests include re-entry, correctional practices, and desistance.

Tenille Ford is a corrections practitioner with expertise in case management and the delivery of correctional interventions. She received her Master of Criminology and Criminal Justice from Griffith University in 2019. 